\title{
Novel Molybdenite-Based Nanopowder Catalysts for Hydrodesulfurization
}

\author{
T. A. Fedushchak ${ }^{a, *}$, M. A. Uimin ${ }^{b}$, V. V. Maikov ${ }^{b}$, A. S. Akimov ${ }^{a}$, S. P. Zhuravkov ${ }^{c}$, \\ A. V. Vosmerikov ${ }^{a}$, I. P. Prosvirin ${ }^{d}$, L. M. Velichkina ${ }^{a}$, A. A. Stepanov ${ }^{a}$, and V. M. Kogan ${ }^{e}$ \\ ${ }^{a}$ Institute of Petroleum Chemistry, Siberian Branch of Russian Academy of Sciences (IPC SB RAS), Tomsk, 634050 Russia \\ ${ }^{b}$ Mikheev Institute of Metal Physics, Ural Branch of Russian Academy of Sciences (IMP UB RAS), Yekaterinburg, 620137 Russia \\ ${ }^{c}$ Tomsk Polytechnic University, Tomsk, 634050 Russia \\ ${ }^{d}$ Boreskov Institute of Catalysis, Siberian Branch of Russian Academy of Sciences (BIC SB RAS), Novosibirsk, 630090 Russia \\ ${ }^{e}$ Zelinsky Institute of Organic Chemistry, Russian Academy of Sciences, Moscow, 119991 Russia \\ *e-mail: taina@ipc.tsc.ru
}

Received December 11, 2020; revised March 31, 2021; accepted May 25, 2021

\begin{abstract}
Novel bulk single-component sulfide catalysts were prepared under the conditions of solid-phase dispersion of $\mathrm{MoS}_{2}$ molybdenite at various mechanical treatment times and various amounts of polar and nonpolar liquid microadditives. The chemical degradation of the samples in the air was found to lead to the formation of surface sulfate anions that shield catalytically active Mo sites. Indirect correlations of the hydrodesulfurization ability of $\mathrm{MoS}_{2}$ powders with the concentration of sulfate anions on their surface, and with the aqueous $\mathrm{pH}$ in the powder suspensions, including the dielectric permittivity of the organic dopants, can serve as reference indicators of high catalytic activity in the model reaction of dibenzothiophene hydrogenolysis. The study identified the most active sample able to run for an extended time during multiple cycles without losing its catalytic properties. Also, the paper discusses the dibenzothiophene conversion routes, the product composition, the probable structure of active sites in the catalysts, and the desulfurization degree of diesel fuel components.
\end{abstract}

Keywords: nanopowder catalysts, mechanical activation, dopants, liquid microadditives, catalytic activity, hydrotreatment

DOI: $10.1134 / \mathrm{S} 0965544121070033$

The recent increasing trend in the hydrotreatment of petroleum fuels has been to search for approaches to creating novel oil refining catalysts [1]. One potentially effective solution to this problem involves the use of submicron-scale fine-dispersed catalytic systems as the most suitable for restructuring and "unfolding" of oil globules in slurry processes.

Of particular interest are direct methods for the preparation of bulk sulfide catalysts based on purified mineral molybdenite $\left(\mathrm{MoS}_{2}\right)$ as a dimensional precursor of the active component. Typically, $\mathrm{MoS}_{2}$ is subjected to mechanical grinding in planetary ball mills [2] in an organic solvent medium. During mechanical activation (MA), the deformation and fracturing of large solid fragments is known to be significantly facilitated in liquid media with a high wetting energy. This is due to the forces of electrostatic interaction between liquid dipoles and ions on the crystal surface [3].

A prior study describes grinding of molybdenite in a butanol medium in a planetary ball mill under strong shock impacts on the substrate at high accelerations $(g)$ of 300 to $500 \mathrm{~m}^{2} / \mathrm{s}$ [4]. The nanocrystallites obtained in this manner had a disadvantage: due to carbonization, they lost their catalytic activity as early as after the first service cycle in a model reaction of dibenzothiophene (DBT) hydrodesulfurization (HDS) and in hydrotreatment of petroleum feedstock. The authors of the referenced study provide no explanation for this.

It should be noted that researchers have traditionally attempted to find conditions to prepare samples with the highest possible defect level [4]. These attempts are consistent with classical approaches to the preparation of 
MA materials with pronounced catalytic properties [5]. The highest-shock-impact mode has generally been used to achieve "high-defect" grinding of molybdenite [4]. However, it is well known that $\mathrm{MoS}_{2}$, as a $d$-transition metal dichalcogenide with a layered structure, can form intercalation compounds (i.e., compounds inserted between adjacent layers) and exfoliate (split into single nanocrystals).

Previously, we reported on the development of a one-step direct method for preparing $\mathrm{MoS}_{2}$ catalytic nanosystems under dry molybdenite grinding conditions [6]. The method was implemented in a vibratory mill in the presence of small amounts of methanol or water at low grinding media accelerations $\left(g \leq 50 \mathrm{~m}^{2} / \mathrm{s}\right)$. Under shear stresses, the $\mathrm{MoS}_{2}$ layers are mostly exposed to longitudinal fragmentation. This leads to their layerby-layer displacement, mixing, and grinding in the plastic strain mode, followed by the formation of $\mathrm{MoS}_{2}$ nanocrystallites. The temperature of dopant removal from the $\mathrm{MoS}_{2}$ samples (the dopant being represented by methanol or water) proved to exceed the boiling points of these dopants by $70-100^{\circ} \mathrm{C}$. This finding suggests that the dopants are chemically and structurally bound with molybdenite's interlayer space. Unfortunately, the data available from published reports on the structure and properties of such systems are insufficient.

The purpose of the present study was to prepare powder HDS catalysts in one step by direct grinding of molybdenite in the presence of small amounts of polar and nonpolar liquids, to measure their physicochemical properties, as well as to determine their catalytic activity in a model DBT conversion reaction and in the hydrotreatment of diesel components.

\section{EXPERIMENTAL}

The catalysts were prepared by grinding purified mineral molybdenite (a commercial fine-dispersed $\mathrm{MoS}_{2}$ powder, DMI-7), specifically by mechanical activation in a vibratory mill in the presence (or absence, for comparison purposes) of dopants. The dopants were represented by organic fluids such as methanol, ethanol, butanol, hexane, and water, in amounts of 25-200 $\mu \mathrm{L}$ per $3 \mathrm{~g}$ of molybdenite. The molybdenite was dispersed under the following conditions: grinding media acceleration $g \leq 50 \mathrm{~m}^{2} / \mathrm{s}$; frequency $16 \mathrm{~Hz}$; amplitude $2 \mathrm{~mm}$; ball diameter $20 \mathrm{~mm}$; predominant shear stresses; MA time $\left(\tau_{\mathrm{MA}}\right)$ equals $0.5,5.0,8.0,12.0$, and $16.0 \mathrm{~h}$. The following exemplary notation was used for the catalyst samples:
$* \mathrm{MoS}_{2}+100 \mathrm{CH}_{3} \mathrm{OH}(8)$, which indicates that the sample was mechanically activated (as denoted by the asterisk) in the presence of $100 \mu \mathrm{L}$ of methanol for $8 \mathrm{~h}$.

The specific surface area of the prepared catalysts was measured using the Brunauer-Emmett-Teller (BET) method on a Sorptometer-M instrument.

The surface morphology of the catalysts was identified by transmission electron microscopy (TEM) on CM-30 (Philips Netherlands) and JEM-2010 (JEOL Japan) instruments.

$\mathrm{X}$-ray diffraction (XRD) of the prepared samples was performed using a D8-Discover diffractometer (Bruker Germany) in a $2 \theta$ range of $8^{\circ}-46^{\circ}$ in monochromated $\mathrm{Cu} K_{\alpha}$ radiation. The coherent scattering regions (CSR) of the samples were used to measure the nanocrystallite dimensions (in terms of the basal face length, $L$ ). The interplanar distances, also referred to as $d$-spacings $\left(D_{002}\right)$, were calculated using the Debye-Scherrer equation [7]. The contribution of microstrains was derived from variations in $D_{002}$ and internal elastic microstrains $(\Delta d / d)$. The crystallographic defects and microstrains were evaluated by variations in the unit cell parameters (c/a).

X-ray photoelectron spectra (XPS) of the $\mathrm{MoS}_{2}$ samples were recorded on a SPECS photoelectron spectrometer using AlK $*$ radiation $\left(h^{*}=1486.6 \mathrm{eV}\right)$. The binding energy scale $\left(E_{\mathrm{b}}\right)$ was pre-calibrated according to the peak positions of the ground energy levels for gold $\left(\mathrm{Au} 4 f_{7 / 2}, 84.0 \mathrm{eV}\right)$ and copper $\left(\mathrm{Cu}_{2} p_{3 / 2}, 932.67 \mathrm{eV}\right)$. The powdered samples were deposited onto a biadhesive conductive copper tape. For calibration, the $\mathrm{C} 1 s$ line $\left(E_{\mathrm{b}}=284.8 \mathrm{eV}\right)$ of carbon present on the catalyst surface was used. In $\mathrm{MoS}_{2}$, peaks at $162.3 \mathrm{eV}$ (sulfide) and $169.2 \mathrm{eV}$ (partially oxidized sulfur) correspond to the binding energies of S2p, whereas a peak at $229.2 \mathrm{eV}$ (typical $\mathrm{Mo}^{4+}$ state) is attributed to Mo3d. The $\mathrm{C} 1$ s peak is located at $284.8 \mathrm{eV}$.

The depth variations in the atomic concentrations of elements were measured by ion etching of the sample surface. The etching was carried out using a SPECS IQE $11 / 35$ ion gun with argon ion energy of $1.05 \mathrm{kV}$ and a current density of $6.8 \mu \mathrm{A} / \mathrm{cm}^{2}$. The chemical state of the elements on a sample's surface was identified by recording individual spectral bands. The lines of $\mathrm{S} 2 p$, $\mathrm{S} 2 s+\mathrm{Mo} 3 d, \mathrm{C} 1 s$, and $\mathrm{O} 1 s$ were recorded [8].

IR spectra of the powders were recorded on a SPECORDM-80 spectrophotometer using $\mathrm{KBr}$ tablets. 
(a)

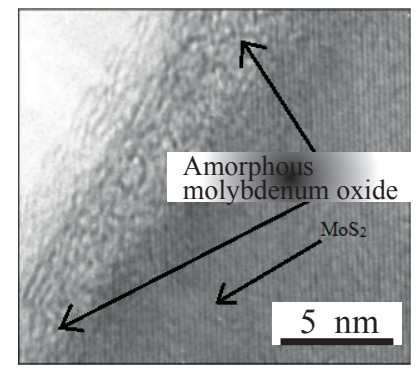

(b)

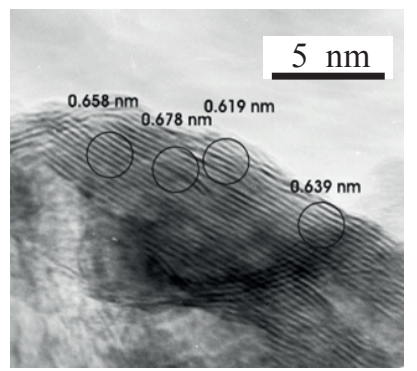

(c)

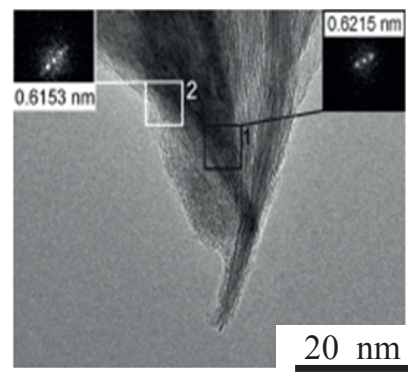

(d)

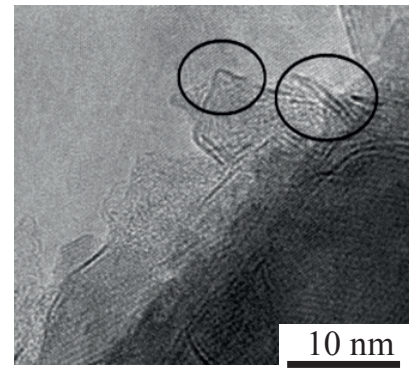

Fig. 1. Electron micrographs of catalysts: (a) initial molybdenite DMI-7; (b) $* \mathrm{MoS}_{2}(8)$; (c) $* \mathrm{MoS}_{2}+100 \mathrm{CH} 3 \mathrm{OH}(8)$ before model reaction; and (d) $* \mathrm{MoS}_{2}+100 \mathrm{CH}_{3} \mathrm{OH}(8)$ after model reaction.

The aqueous acidity of the powder suspensions was determined potentiometrically using a HANNA Instruments microprocessor-based laboratory $\mathrm{pH}$ meter.

The activity of the MA-MoS 2 samples was evaluated in a model DBT conversion reaction $\left(\mathrm{S}_{\text {init }}=500 \mathrm{ppm}\right)$ from the residual sulfur concentration $\left(\mathrm{S}_{\text {res }}\right)$ in the HDS product and the DBT conversion rate constants $\left(k, \mathrm{~h}^{-1}\right)$ [9]. The experiments were carried out in a $100 \mathrm{~mL}$ Autoclave Engineers Bolted Closure reactor at $340^{\circ} \mathrm{C}$, a hydrogen pressure of $3.4 \mathrm{MPa}$, and a stirring speed of $600 \mathrm{rpm}$, in $80 \mathrm{~mL}$ of a hexadecane solution for a reaction time of $0.5-16 \mathrm{~h}$. The initial concentration of DBT $(0.17 \mathrm{~g})$ in a sulfur equivalent amounted to $S_{\text {init }}=500 \mathrm{ppm}$. The weight of the catalyst sample was $0.64 \mathrm{~g}$.

The catalyst placed into the reactor was held under a nitrogen flow at $150^{\circ} \mathrm{C}$ for $1 \mathrm{~h}$, then during the activation step in an $\mathrm{H}_{2}+\mathrm{H}_{2} \mathrm{~S}(9: 1)$ atmosphere at $390^{\circ} \mathrm{C}$. The catalyst weight was $0.64 \mathrm{~g}$, and the volume of DBT-containing $n$-hexadecane was $80 \mathrm{~mL}$. After the reaction, the liquid phase and the powder were separated by decantation. The hexadecane was tested for residual sulfur $\left(\mathrm{S}_{\text {res }}\right)$ by X-ray fluorescence (XRF) on a Spectroscan SW-D3 instrument. The composition of the model reaction product was identified by chromatography-mass spectrometry (GC/MS) on a DFS magnetic GC/MS instrument (Thermo Scientific Germany).

The catalyst identified during the experiments as the most active was subsequently used for the hydrotreatment of the mixed diesel fuel (DF) components. The hydrotreatment was carried out in a stationary autoclaving mode, using mixed DF from the Ryazan refinery (90 wt \% straight-run and $10 \mathrm{wt} \%$ from catalytic cracking) as a feedstock. The DF initially contained 2.08 wt \% sulfur, $184 \mathrm{ppm}$ nitrogen, and $48.9 \mathrm{wt} \%$ aromatic hydrocarbons, and had a density of $0.8574 \mathrm{~g} / \mathrm{cm}^{3}$. Before being placed into the reactor, the DF was diluted in $n$-hexadecane at $1: 40.2$ to correspond to $\mathrm{S}_{\text {init }}=500 \mathrm{ppm}$, as in the model reaction for DBT.

\section{RESULTS AND DISCUSSION}

Figures 1a-1d provide electron micrographs of the initial molybdenite DMI-7 (Fig. 1a), of the methanolcontaining nanocrystalline sample prepared by grinding $\mathrm{MoS}_{2}$ without dopants (Fig. 1b), and of the sample before the model reaction (Fig. 1c) and after the model reaction (Fig. 1d).

The Fourier transform of areas 1 and 2 in the methanolcontaining sample (Fig. 1c) visualizes a typical set of planes (002) and (103) in the $\mathrm{MoS}_{2}$ hexagonal structure with $d$-spacings of 0.6153 and $0.6217 \mathrm{~nm} \mathrm{[10].} \mathrm{The}$ dispersion of $* \mathrm{MoS}_{2}+100 \mathrm{CH}_{3} \mathrm{OH}(8)$ increases after the model reaction (Fig. 1d). The low-oriented single-layer and multilayer $\mathrm{MoS}_{2}$ structures with a linear dimension $L \geq 20 \mathrm{~nm}$ and a stacking number of 10 to 20 contain multiple defects and agglomerates (Figs. 1b and 1c). The stacked nanocrystallites are distinguished by angular shifts and exfoliation after the reaction (Fig. 1d).

Figure 2 illustrates the XRD patterns of the samples, whereas Table 1 presents the results of their processing, including the basal face length of $\mathrm{MoS}_{2}$ nanocrystallites ( $L$ for CSRs), the d-spacings $\left(D_{002}\right)$, the internal elastic stresses $(\Delta d / d)$, and the microstrains in unit cells (c/a) induced by MA.

In an inert medium without dopants (samples nos. 1-3), an increase in MA time in the series $0 \ldots 4 \ldots 8 \mathrm{~h}$ reduces the average basal face length of the resultant $\mathrm{MoS}_{2}$ nanocrystallites from 50 to 20 and $12 \mathrm{~nm}$, respectively (see Table 1 and Fig. 2). Simultaneously, the 
internal elastic stresses $\left(\Delta d / d \times 10^{3}\right)$ and the microstrains in unit cells (c/a) rise in the series 2.1...2.6...8.8 and $3.89 \ldots 3.91 \ldots 3.95$, respectively (Table 1 ). In contrast to water (sample no. 4$)$, methanol ( $\tau_{\mathrm{MA}}=8 \mathrm{~h}$, sample no. 5 ) inhibits the grinding of the initial coarse-crystalline substrate (DMI-7) and eliminates the defects (c/a). The average basal face length of the $\mathrm{MoS}_{2}$ nanocrystallites in the presence of methanol $(L=25 \mathrm{~nm})$ is almost twice as high as that in the water-doped case $(13 \mathrm{~nm})$. The methanol incrementation from 100 to $200 \mu \mathrm{L}$ (samples no. 5 vs. no. 6 , with $\tau_{\mathrm{MA}}=8 \mathrm{~h}$ ) only very slightly affects the powder dispersion ( 25 vs. $24 \mathrm{~nm}$, respectively). A similar effect was observed for the 100 and $200 \mu \mathrm{L}$ methanol in the $12 \mathrm{~h}$ case (samples no. 7 vs. no. 8), where the difference in the dispersion of MA molybdenite particles is insignificant (10 vs. $14 \mathrm{~nm}$ ).

According to published reports, in supported catalysts such as $\mathrm{Ni}(\mathrm{Co})-\mathrm{Mo}(\mathrm{W})-\mathrm{S} / \gamma-\mathrm{Al}_{2} \mathrm{O}_{3}$, the optimal size of $\mathrm{MoS}_{2}$ nanocrystallite stacks on the support surface is 4$5 \mathrm{~nm}$ with an average of $1.5 \pm 0.4$ layers per stack [11]. However, in the case of bulk catalysts prepared under thermal decomposition of ammonium thiomolybdate followed by grinding of the resultant $\mathrm{MoS}_{2}$ in a solvent medium, the average length of ordered CSRs $(L)$ is 20-30 nm, with up to 10-15 layers per nanocrystallite stack [12]. In the prepared catalyst samples, the number of single layers per stack is 10-20. The length of basal planes exceeds $15-20 \mathrm{~nm}$. In a previous study by the same researchers, where molybdenite was ground in a liquid medium with butanol excess, the prepared catalyst powder had a specific surface area of $81 \mathrm{~m}^{2} / \mathrm{g}$ [4].

The $\mathrm{MoS}_{2}$ powders examined in the present study were prepared in one step by mechanical grinding of purified mineral molybdenite. They are also nanocrystallites with

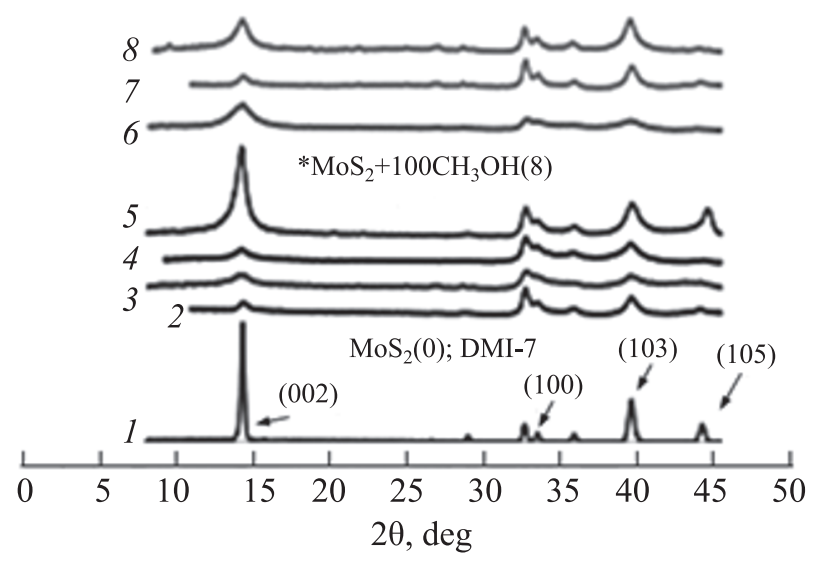

Fig. 2. XRD patterns of $\mathrm{MoS}_{2}$ samples.

an average size of $L<50 \mathrm{~nm}$ (Table 1). However, they have unexpectedly low specific surface areas $\left(S_{\mathrm{sp}}=1.5-\right.$ $2.2 \mathrm{~m}^{2} / \mathrm{g}$ ), in contrast to the previously described systems $[4,11,12]$. Below is a probable explanation.

In the chemistry of metal nanopowders, the differences in BET parameters (Table 1) are usually attributed to agglomeration and conglomeration of nanoparticles and to the generation of new bulk hierarchical structures [13]. The energy saturation in nanostructures is known to be eliminated by relaxation of internal stresses in crystallites as well as by mutual collapses of the exposed faces of nanoparticles. On the other hand, the chemical degradation of nanosystems is caused by the secondary conversion of unstable and metastable surface compounds during their interaction with environmental media. The products may have various adhesion and cohesion strengths. These processes may occur simultaneously, so they are difficult to separate. Therefore, the $S_{\text {sp }}$ values provided in Table 1 are, in fact, "apparent" values corresponding

Table 1. XRD characteristics of $\mathrm{MoS}_{2}$ nanocrystallites and BET specific surface area of powders ${ }^{\mathrm{a}}$

\begin{tabular}{c|l|c|c|c|c|c}
\hline Sample no. & \multicolumn{1}{|c|}{ Catalyst } & $L, \mathrm{~nm}$ & $D_{002}, \AA$ & $\Delta d / d \times 10^{3}$ & $\mathrm{c} / \mathrm{a}$ & $S_{\text {sp }}, \mathrm{m}^{2} / \mathrm{g}$ \\
\hline 1 & $\mathrm{MoS}_{2}(0)(\mathrm{DMI}-7)$ & 50 & 6.15 & 2.1 & 3.888 & 0.19 \\
2 & $* \mathrm{MoS}_{2}(4)$ & 20 & 6.15 & 2.6 & 3.909 & - \\
3 & $* \mathrm{MoS}_{2}(8)$ & 12 & 6.20 & 8.8 & 3.954 & 2.0 \\
4 & $* \mathrm{MoS}_{2}+100 \mathrm{H}_{2} \mathrm{O}(8)$ & 13 & 6.19 & 3.5 & 3.921 & 1.7 \\
5 & $* \mathrm{MoS}_{2}+100 \mathrm{CH}_{3} \mathrm{OH}(8)$ & 25 & 6.19 & 2.3 & 3.912 & 1.8 \\
6 & $* \mathrm{MoS}_{2}+200 \mathrm{CH}_{3} \mathrm{OH}(8)$ & 24 & 6.15 & 3.0 & 3.906 & 1.5 \\
7 & $* \mathrm{MoS}_{2}+100 \mathrm{CH}_{3} \mathrm{OH}(12)$ & 10 & 6.17 & 8.6 & 3.945 & - \\
8 & $* \mathrm{MoS}_{2}+200 \mathrm{CH}_{3} \mathrm{OH}(12)$ & 14 & 6.17 & 2.4 & 3.916 & 2.2 \\
\hline
\end{tabular}

${ }^{a}$ The notation principle for the MA samples (MA time, doped liquid, and its volume) is described in Experimental. 
Table 2. XPS characteristics of catalyst samples prepared by mechanical grinding of molybdenite $\left(\tau_{\mathrm{MA}}=8 \mathrm{~h}\right)$

\begin{tabular}{|c|c|c|c|c|}
\hline \multirow{2}{*}{$\begin{array}{l}\text { Sample } \\
\text { code }^{\mathrm{a}}\end{array}$} & \multirow{2}{*}{ MA catalysts } & \multicolumn{2}{|c|}{ Ratio } & \multirow{2}{*}{$\mathrm{SO}_{4}^{2-}, \%$} \\
\hline & & S/Mo & $\mathrm{SO}_{4}^{2-} / \mathrm{S}^{2-}$ & \\
\hline \multicolumn{5}{|c|}{ Group I: Initial $\mathrm{CH}_{3} \mathrm{OH}$-doped catalysts before reaction } \\
\hline \multicolumn{5}{|c|}{ Dopant volume range: $200-25 \mu \mathrm{L}$} \\
\hline S-1 & $* \mathrm{MoS}_{2}+200 \mathrm{CH}_{3} \mathrm{OH}(8)$ & 2.2 & 0.69 & 40.8 \\
\hline S-2 & $* \mathrm{MoS}_{2}+100 \mathrm{CH}_{3} \mathrm{OH}(8)$ & 2.1 & 0.52 & 34.4 \\
\hline S-3 & $* \mathrm{MoS}_{2}+50 \mathrm{CH}_{3} \mathrm{OH}(8)$ & 2.3 & 0.24 & 19.2 \\
\hline S-4 & $* \mathrm{MoS}_{2}+25 \mathrm{CH}_{3} \mathrm{OH}(8)$ & 2.2 & 0.20 & 17.1 \\
\hline \multirow{2}{*}{\multicolumn{5}{|c|}{ Group II: $\mathrm{CH}_{3} \mathrm{OH}$ catalysts with $\mathrm{Ar}^{+}$etched surface before reaction }} \\
\hline & & & & \\
\hline S-1-Ar & $* \mathrm{MoS}_{2}+200 \mathrm{CH}_{3} \mathrm{OH}(8)-\mathrm{Ar}$ & 1.4 & 0.28 & 21.8 \\
\hline $\mathrm{S}-2-\mathrm{Ar}$ & $* \mathrm{MoS}_{2}+100 \mathrm{CH}_{3} \mathrm{OH}(8)-\mathrm{Ar}$ & 1.2 & 0.21 & 17.2 \\
\hline $\mathrm{S}-3-\mathrm{Ar}$ & $* \mathrm{MoS}_{2}+50 \mathrm{CH}_{3} \mathrm{OH}(8)-\mathrm{Ar}$ & 1.8 & 0.10 & 9.3 \\
\hline $\mathrm{S}-4-\mathrm{Ar}$ & $* \mathrm{MoS}_{2}+25 \mathrm{CH}_{3} \mathrm{OH}(8)-\mathrm{Ar}$ & 1.3 & 0.06 & 5.5 \\
\hline \multicolumn{5}{|c|}{ Group III: Catalysts before reaction } \\
\hline \multicolumn{5}{|c|}{ Dopants $^{\mathrm{a}}$ : methanol, ethanol, butanol, and hexane. Volume: $100 \mu \mathrm{L}$} \\
\hline S-2 & $* \mathrm{MoS}_{2}+100 \mathrm{CH}_{3} \mathrm{OH}(8)$ & 2.1 & 0.52 & 34.4 \\
\hline S-5 & $* \mathrm{MoS}_{2}+100 \mathrm{C}_{2} \mathrm{H}_{5} \mathrm{OH}(8)$ & 2.2 & 0.31 & 23.7 \\
\hline S-6 & $* \mathrm{MoS}_{2}+100 \mathrm{C}_{4} \mathrm{H}_{9} \mathrm{OH}(8)$ & 2.2 & 0.24 & 19.1 \\
\hline S-7 & $* \mathrm{MoS}_{2}+100 \mathrm{C}_{6} \mathrm{H}_{14}(8)$ & 2.1 & 0.25 & 20.0 \\
\hline \multicolumn{5}{|c|}{ Group IV: Samples from Group III with $\mathrm{Ar}^{+}$etched surface } \\
\hline S-2-Ar & $* \mathrm{MoS}_{2}+100 \mathrm{CH}_{3} \mathrm{OH}(8)-\mathrm{Ar}$ & 1.2 & 0.21 & 17.2 \\
\hline $\mathrm{S}-5-\mathrm{Ar}$ & $* \mathrm{MoS}_{2}+100 \mathrm{C}_{2} \mathrm{H}_{5} \mathrm{OH}(8)-\mathrm{Ar}$ & 1.3 & 0.10 & 8.8 \\
\hline S-6-Ar & $* \mathrm{MoS}_{2}+100 \mathrm{C}_{4} \mathrm{H}_{9} \mathrm{OH}(8)-\mathrm{Ar}$ & 1.4 & 0.06 & 6.1 \\
\hline S-7-Ar & $* \mathrm{MoS}_{2}+100 \mathrm{C}_{6} \mathrm{H}_{14}(8)-\mathrm{Ar}$ & 1.3 & 0.09 & 8.6 \\
\hline \multicolumn{5}{|c|}{ Group V: Catalysts after reaction } \\
\hline S-2-1 & $* \mathrm{MoS}_{2}+100 \mathrm{CH}_{3} \mathrm{OH}(8)$ & 1.2 & 0.03 & 3.0 \\
\hline S-5-1 & $* \mathrm{MoS}_{2}+100 \mathrm{C}_{2} \mathrm{H}_{5} \mathrm{OH}(8)$ & 1.3 & 0.04 & 5.0 \\
\hline \multicolumn{5}{|c|}{ Group VI: Catalysts after reaction and after $\mathrm{Ar}^{+}$etching $(10 \mathrm{~min})$} \\
\hline S-2-1-Ar & $* \mathrm{MoS}_{2}+100 \mathrm{CH}_{3} \mathrm{OH}(8)-\mathrm{Ar}$ & 1.2 & 0 & 0 \\
\hline $\mathrm{S}-5-1-\mathrm{Ar}$ & $* \mathrm{MoS}_{2}+100 \mathrm{C}_{2} \mathrm{H}_{5} \mathrm{OH}(8)-\mathrm{Ar}$ & 1.3 & 0 & 0 \\
\hline
\end{tabular}

${ }^{a}$ Liquid dopants in Group III are listed in descending order of dielectric permittivity.

to agglomerated nanocrystallites. The causes of the agglomeration are described below (Table 2).

For heterogeneous systems, any chemical interaction is well known to begin at the interface. Therefore, for the purposes of evaluating the catalytic activity of MA molybdenite samples, the chemical state of their surface is important to know. Table 2 presents data based on the XPS spectra of the powdered $\mathrm{MoS}_{2}$ samples, before and after the model DBT hydrogenolysis reaction. The table also indicates variations in the atomic concentrations of elements across the depth of the surface layer, which were examined by $\mathrm{Ar}^{+}$etching of the surface. The samples are divided into six groups (I-VI). Within the groups, dopants are listed in descending order of dielectric permittivity.

Group I includes the catalysts prepared by mechanical dispersion of $\mathrm{MoS}_{2}$ in the presence of 200-25 $\mu \mathrm{L}$ of $\mathrm{CH}_{3} \mathrm{OH}$. The XPS characteristics for this group show that decreasing the dopant volume in the series $200 \ldots 100 \ldots 50 \ldots 25 \mu \mathrm{L}$ reduces the concentration of $\mathrm{SO}_{4}^{2-}$ anions on the $\mathrm{MoS}_{2}$ nanopowder surface from about $40 \%$ to about $17 \%$. The sulfate-to-sulfide ratio $\left(\mathrm{SO}_{4}^{2-} / \mathrm{S}^{2-}\right)$ also synchronously declines from 0.69 to 0.20 . These trends are also observed for the same samples after $\mathrm{Ar}^{+}$etching of their surface (Table 2, Group II). 


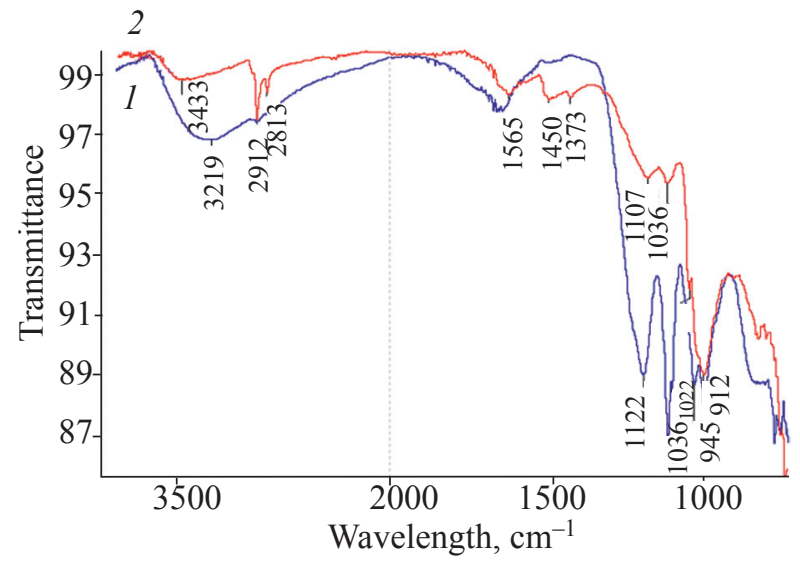

Fig. 3. IR spectra of samples: (1) before and (2) after reaction.

For the samples of Group III, prepared in the presence of $100 \mu \mathrm{L}$ of alcohols and hexane, the variation trends are different. The quantities of sulphate anions on the surface of molybdenite powders with $n$-butanol and $n$-hexane are almost equal (19-20\%). So are the respective $\mathrm{SO}_{4}^{2-} /$ $\mathrm{S}^{2-}$ ratios $(0.24-0.25)$. In contrast, the $\mathrm{CH}_{3} \mathrm{OH}$-doped sample (S-2) and the $\mathrm{C}_{2} \mathrm{H}_{5} \mathrm{OH}$-doped sample (S-5) have obvious differences: 34.4 and $23.7 \% \mathrm{SO}_{4}^{2-}$, respectively.

On the other hand, for the hexane-containing sample of Group IV (S-7-Ar), the surface affinity of $\mathrm{SO}_{4}^{2-}$ anions is as pronounced as for the ethanol-containing $\mathrm{MoS}_{2}$ (S-5-Ar). Sulfate anions are present in amounts of $8.6 \%$ and $8.8 \%$, respectively.

Catalysts S-2-1 and S-5-1, obtained after the model DBT HDS reaction, are classified as Group V. As compared to S-2 and S-5, the presence of sulfate anions declines by a factor of 11 and 5, respectively. Moreover, their bonds with the catalyst surface become so weak that, after subsequent irradiation with $\mathrm{Ar}^{+}$ions (Group VI), the surface sulfate anions are not detected at all $(0 \%)$.

The IR spectra of $* \mathrm{MoS}_{2}+100 \mathrm{CH}_{3} \mathrm{OH}(8)$ before and after the reaction (spectra 1 and 2, respectively, in Fig. 3) agree with, and add to, the above XPS data. The surface of the initial powder (Fig. 3, 1) exhibits a bending band of weakly adsorbed water near $1630 \mathrm{~cm}^{-1}$, in addition to bands that can be attributed to the sulfate ion $\left(\mathrm{SO}_{4}^{2-}\right)$ vibrations $\left(1150-850 \mathrm{~cm}^{-1}\right)$. The frequency bands near $1016-1118 \mathrm{~cm}^{-1}$ and $1144-617 \mathrm{~cm}^{-1}$ serve as evidence of the valence vibrations of the bonds: $v(\mathrm{~S}-\mathrm{O} ; \mathrm{S}=\mathrm{O})$ and $v(\mathrm{Mo}-\mathrm{O}-\mathrm{Mo}$ or $\mathrm{Mo}=\mathrm{O})$ and $\mathrm{SO}_{4}^{2-}$. Although the

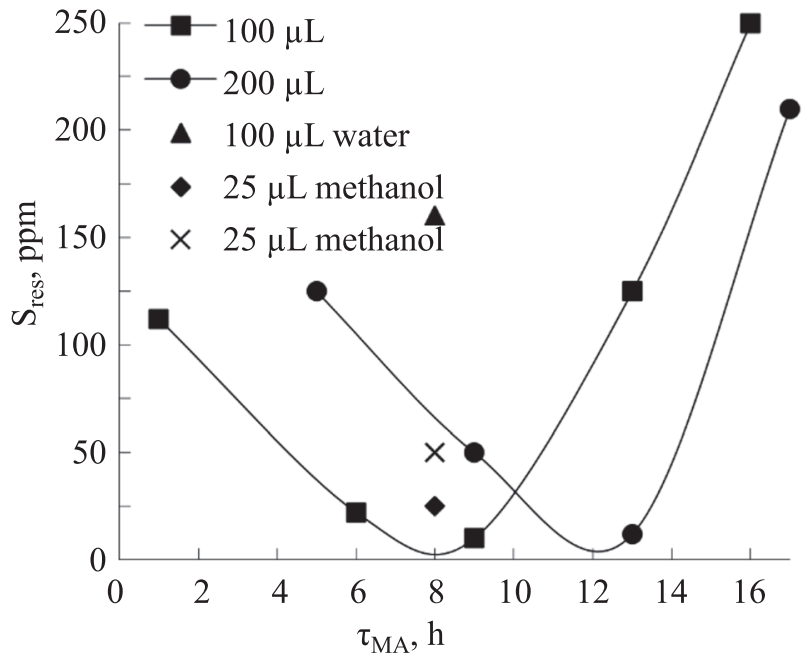

Fig. 4. HDS ability of molybdenite powder samples as a function of molybdenite grinding time and amount of dopants.

catalyst's spectrum after the reaction (Fig. 3,2) is much less congested, it indicates the presence of molybdenum oxides on the surface.

Some additional points should also be noted. According to published data, sulfate anions or their precursors can primarily exist on the powder surface in covalently bound forms [14]. At the same time, due to interaction with air moisture (Fig. 3, 1), trace amounts of acids may also be present on the surface (Table 2). Obviously, this very presence is directly responsible for the above-mentioned agglomeration of powder nanoparticles and for the low $S_{\mathrm{sp}}$ values (see Table 1). When labile compounds ingress from the powder surface into the aqueous medium, corresponding acids are readily formed. The addition of barium chloride to the aqueous phase of powder suspensions leads to a curdy precipitate of barium sulfate, which represents an analytical test for the presence of sulfate anions [15] and sulfuric acid. It is not only sulfate anions that can act as $\mathrm{H}_{2} \mathrm{SO}_{4}$ precursors. Precursors can also be other readily hydrolysable $\mathrm{S}-\mathrm{O}-$ and $\mathrm{O}=\mathrm{S}$-containing compounds able to pass from the surface of catalyst particles into the aqueous phase, thus causing low $\mathrm{pH}$ values (Table 3 ) and the agglomeration of powder particles.

Figure 4 shows the preliminary screening data on the efficiency of DBT HDS (in terms of $\mathrm{S}_{\text {res }}$ ) in the presence of samples prepared within the molybdenite dispersion time interval of $0.5-16.0 \mathrm{~h}$ with methanol doped in amounts of $25-200 \mu \mathrm{L}$. We clearly see that increasing the methanol amount from 100 to $200 \mu \mathrm{L}$ necessarily (to 
Table 3. Catalysts, aqueous $\mathrm{pH}$ in powder suspensions, HDS ability, and DBT HDS product composition

\begin{tabular}{|c|c|c|c|c|c|c|c|c|}
\hline \multirow{2}{*}{$\begin{array}{c}\text { Sample } \\
\text { code }\end{array}$} & \multirow{2}{*}{ Catalyst } & \multirow{2}{*}{$\mathrm{S}_{\mathrm{res}}, \mathrm{ppm}^{\mathrm{a}}$} & \multicolumn{4}{|c|}{ Product composition ${ }^{\mathrm{b}}, \%$} & \multirow{2}{*}{$\mathrm{pH}^{\mathrm{c}}$} & \multirow{2}{*}{ Constant $^{\mathrm{d}}, k, \mathrm{~h}^{-1}$} \\
\hline & & & $\mathrm{BPh}$ & $\mathrm{CHB}$ & THDBT & $\mathrm{BCH}$ & & \\
\hline 1 & $\mathrm{MoS}_{2}(0) ;(\mathrm{DMI}-7)$ & 405 & - & - & - & - & 2.44 & 0.22 \\
\hline 1.1 & $* \mathrm{MoS}_{2}(8)$ & 105 & 53.8 & 45.6 & 0.61 & Zero & 2.10 & 0.46 \\
\hline 1.2 & $* \mathrm{MoS}_{2}+100 \mathrm{H}_{2} \mathrm{O}(8)$ & 161 & 44.2 & 53.7 & 2.12 & Zero & 2.11 & 0.25 \\
\hline 1.3 & $* \mathrm{MoS}_{2}+200 \mathrm{CH}_{3} \mathrm{OH}(12)$ & 7 & 49.0 & 50.0 & 1.03 & Zero & 2.80 & 0.35 \\
\hline S-1 & $* \mathrm{MoS}_{2}+200 \mathrm{CH}_{3} \mathrm{OH}(8)$ & 50 & 88.2 & 11.1 & 0.70 & Zero & 2.60 & 0.39 \\
\hline S-2 & $* \mathrm{MoS}_{2}+100 \mathrm{CH}_{3} \mathrm{OH}(8)$ & 3 & 43.0 & 57.0 & Zero & Zero & 2.10 & 0.65 \\
\hline S-3 & $* \mathrm{MoS}_{2}+50 \mathrm{CH}_{3} \mathrm{OH}(8)$ & 25 & 92.9 & 7.1 & 0.09 & Zero & 2.30 & 0.38 \\
\hline S-4 & $* \mathrm{MoS}_{2}+25 \mathrm{CH}_{3} \mathrm{OH}(8)$ & 47 & 83.6 & 13.2 & 3.21 & 0.13 & 2.56 & $-^{\mathrm{e}}$ \\
\hline S-5 & $* \mathrm{MoS}_{2}+100 \mathrm{C}_{2} \mathrm{H}_{5} \mathrm{OH}(8)$ & 20 & 91.1 & 8.9 & Zero & Zero & 2.27 & 0.40 \\
\hline S-6 & $* \mathrm{MoS}_{2}+100 \mathrm{C}_{4} \mathrm{H}_{9} \mathrm{OH}(8)$ & 28 & 94.2 & 5.8 & Zero & Zero & 2.38 & 0,41 \\
\hline S-7 & $* \mathrm{MoS}_{2}+100 \mathrm{C}_{6} \mathrm{H}_{8}(8)$ & 47 & 91.4 & 8.6 & Zero & Zero & 2.41 & - \\
\hline 1.4 & Blank sample & 470 & - & - & - & - & 2.44 & - \\
\hline
\end{tabular}

${ }^{a}$ DBT-HDS ability of powder.

${ }^{\mathrm{b}} \mathrm{GC} / \mathrm{MS}$ composition of model reaction products, where $\mathrm{BPh}$ is biphenyl; CHB is cyclohexylbenzene; THDBT is tetrahydrodibenzothiophene; and $\mathrm{BCH}$ is bicyclohexyl.

${ }^{\mathrm{c}}$ Aqueous $\mathrm{pH}$ in powder suspension.

${ }^{\mathrm{d}}$ DBT conversion rate constant, $k, \mathrm{~h}^{-1}$.

e The notation "-" refers to lack of data.

${ }^{\mathrm{f}} 0.01 \mathrm{~mL}$ of $\mathrm{H}_{2} \mathrm{SO}_{4}$ was taken instead of powder catalyst.

achieve a required HDS degree) extends the MA grinding time from 8 to $12 \mathrm{~h}$. It is only under this condition that the residual sulfur content $\left(\mathrm{S}_{\text {res }}\right)$ decreases from 50 to $7 \mathrm{ppm}$. Based on the findings illustrated in Figure 4, most experiments in this study were carried out on the samples with $\tau_{\mathrm{MA}}=8 \mathrm{~h}$ (Table 3 ).

The Table 3 data on samples S-1, S-2, S-3, and S-4 prepared with $\tau_{\mathrm{MA}}=8 \mathrm{~h}$ (see also Fig. 3) show that a decrease in the amount of methanol dopant from $200 \mu \mathrm{L}$ to 100,50 , and $25 \mu \mathrm{L}$ affects the $\mathrm{S}_{\text {res }}$ in the DBT HDS products according to the following trend: $50 \ldots 3 \ldots 25 \ldots$ $47 \mathrm{ppm}$, respectively. Moreover, a difference in the methanol amount as small as $50 \mu \mathrm{L}$ leads to an eight-fold drop in the residual sulfur content in the HDS product $\left(\mathrm{S}_{\text {res }}=25 \mathrm{ppm}\right.$ for $\mathrm{S}-3$ vs. $\mathrm{S}_{\text {res }}=3 \mathrm{ppm}$ for $\left.\mathrm{S}-2\right)$. This suggests a threshold type of activity growth for S-2. Such effects indicate the high structural sensitivity of molybdenite to the amount of methanol doped during MA and to resulting changes in the catalytic activity of the samples. This may be due to the layered structure of the substrate.

Table 3 also clearly shows that samples 1.3 and S-2 provide the highest DBT conversion degree, as indicated by the lowest $\mathrm{S}_{\text {res }}$ (7 and 3 ppm, respectively). However, the reaction rate constants for these two samples differ by a factor of nearly two ( 0.35 and 0.65 , respectively). These samples were prepared using different MA times (12 vs. $8 \mathrm{~h}$ ) and different amounts of methanol dopant (200 vs. $100 \mu \mathrm{L}$ ). The $\mathrm{pH}$ values, which reflect the amounts of sulfate anions and other acid-forming $\mathrm{S}-\mathrm{O}$ structures on the powder surface, are 2.8 vs. 2.1 , respectively. The latter value is the lowest among the entire series of samples under study. The reaction product for S-2 is represented by biphenyl $(\mathrm{BPh})$ and cyclohexylbenzene $(\mathrm{CHB})$ in amounts of $43 \%$ and $57 \%$, respectively (see Table 3 and Fig. 5, reaction route 1 ). The HDS product for sample 1.3 contains $\mathrm{BPh}$ and $\mathrm{CHB}$ in almost equal amounts (49 and $50 \%$, Table 3 ).

For the catalytic system $* \mathrm{MoS}_{2}+200 \mathrm{CH}_{3} \mathrm{OH}(12)$ (Table 3, sample 1.3), one more product component (namely, tetrahydrodibenzothiophene, TDDBT) was detected in an amount of $1 \%$. This compound was not detected in the HDS product for S-2.

The product composition for S-1 $\left({ }^{*} \mathrm{MoS}_{2}+200 \mathrm{CH}_{3} \mathrm{OH}(8)\right)$ is marked by a distinct predominance of $\mathrm{BPh}(88.2 \%$, Table 3$)$, which is significantly different from the S-2 case. The replacement of methanol with ethanol, butanol, and hexane (S-5, S-6, and S-7, respectively) leads to the preferential conversion of DBT to BPh in amounts of $91-94 \%$. The 


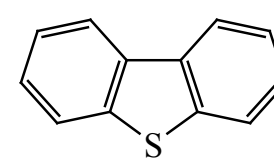

Dibenzothiophene

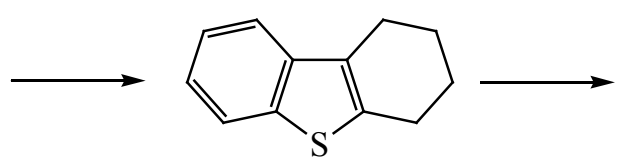

Tetrahydro-DBT

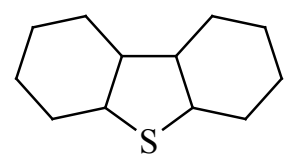

Perahydro-DBT

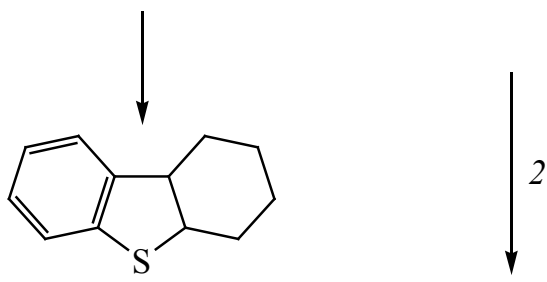

Hexahydro-DBT

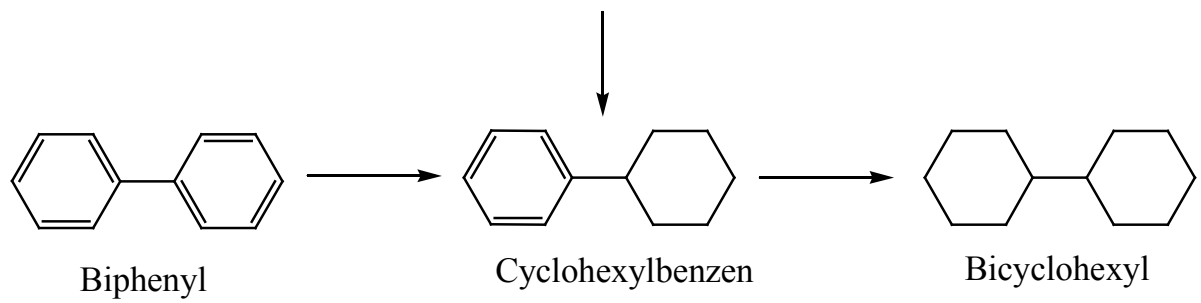

Fig. 5. Reaction scheme of DBT conversion.

catalysts in Table 3 are listed in descending order of the dielectric permittivity $(\varepsilon)$ of the dopants used for their preparation. In accordance with such an approach, the reaction mechanism changes towards an increasing contribution of the cracking ("direct") route (Fig. 5, route 1 ). However, the DBT conversion degree remains low $\left(\mathrm{S}_{\text {res }}=20-47\right)$. The highest DBT HDS rate constant $\left(0.65 \mathrm{~h}^{-1}\right)$ was achieved for S-2.

An interesting result was obtained in the presence of protic $\mathrm{H}_{2} \mathrm{SO}_{4}$ in amounts that ensure $\mathrm{pH} 2.1$ (a value typical of the most active catalyst S-2). In contrast to $\mathrm{S}-2$, the hydrodesulfurizing effect in the model reaction provided by the protic acid catalysis only reaches $\mathrm{S}_{\text {res }}=$ $470 \mathrm{ppm}$ (Table 3, sample 1.4, $\mathrm{S}_{\text {init }}=500 \mathrm{ppm}$ ).

For a more visible representation of the correlation between the XRD and XPS data (Tables 1 and 2) and the catalytic activity of the samples (Table 3), Fig. 6 presents a polynomial curve plotted for the most active samples (Table 3, $\mathrm{S}_{\text {res }}<30 \mathrm{ppm}$ ). This curve indicates the relationship between the residual sulfur and the $\mathrm{BPh}$ content in the product.

The curve in Fig. 6 shows that the high HDS ability of the bulk sulfide catalysts tested in this study leads to biphenyl formation in amounts less than $50 \%$. This corresponds to the cracking route of DBT conversion. In other words, the presence of biphenyl in the DBT HDS product in an amount not exceeding $50 \%$ is not only a marker of the "direct" reaction route, but also points to the high HDS ability of the catalyst examined in the study.

Figure 7 shows a linear correlation for a cluster set of points, which reflects an indirect relationship between the

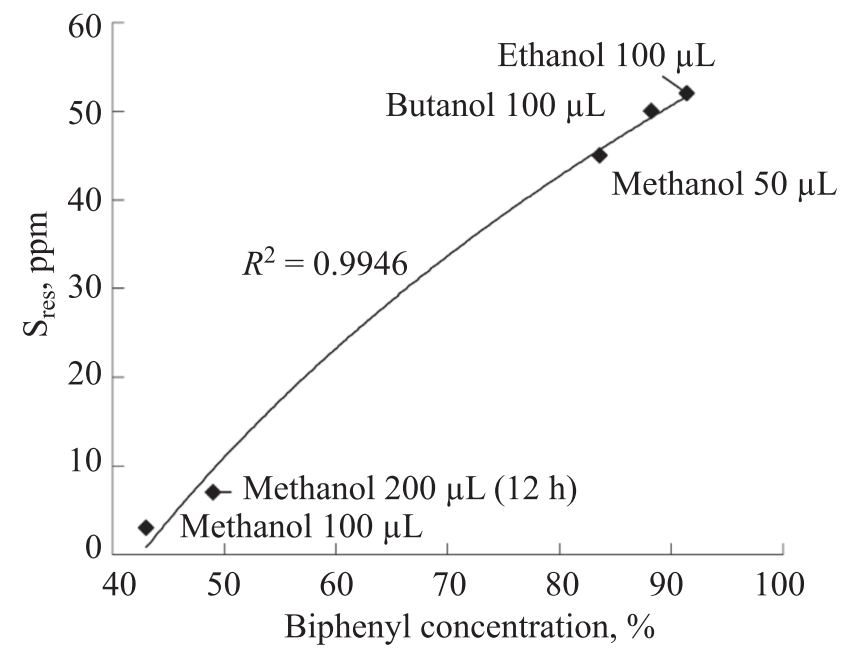

Fig. 6. DBT HDS degree $\left(\mathrm{S}_{\text {res }}\right)$ as a function of $\mathrm{BPh}$ concentration in product $\left(\tau_{\mathrm{MA}}=8 \mathrm{~h}\right.$ and $\left.12 \mathrm{~h}\right)$. 
$\mathrm{pH}$ values in the aqueous phases of the $\mathrm{CH}_{3} \mathrm{OH}$-doped nanopowder suspensions $\left(\tau_{\mathrm{MA}}=8 \mathrm{~h}\right.$, Table 3$)$ and the DBT HDS degree in their presence.

The reliability of linear approximation (Fig. 7) is $R^{2}=0.9927$. The hexane-, water-, and methanol-doped samples with $\tau_{\mathrm{MA}}=12 \mathrm{~h}$ do not fall within the linear correlation area (Fig. 7). It is worth noting that the $\mathrm{pH}$ values in the aqueous phases of the powder suspensions lie in the strong-acidic region of $\mathrm{pH} 2.1-2.6$. For $\mathrm{S}_{\text {res }}<$ $50 \mathrm{ppm}$, the amount of methanol ( 25 to $200 \mu \mathrm{L}$ ) and the HDS ability of the sample do not exhibit pronounced correlations with corresponding $\mathrm{pH}$. However, the aqueous $\mathrm{pH}$ in powder suspensions can be considered as a predictor of the powder's catalytic activity.

A reasonable question is, to what extent the sulfate anions on the MA molybdenite powder's surface are responsible for the $\mathrm{pH}$ values. The answer is more or less provided in Fig. 8a, which shows $S_{\text {res }}$ as a function of the XPS surface concentration of sulfate anions. The upper line reflects a linear relationship between the concentration of sulfate anions on the powder surface $\left(\mathrm{SO}_{4}^{2-}\right)$ and the residual sulfur content in the reaction product for the most active samples $\left(\mathrm{S}_{\text {res }}<30 \mathrm{ppm}\right)$. At the same time, the three powders prepared under somewhat different conditions (the lower line in Fig. 8a) exhibit a low HDS ability $\left(\mathrm{S}_{\mathrm{res}}=\right.$ $47-50 \mathrm{ppm}$ ) within a $\mathrm{SO}_{4}^{2-}$ concentration range of $8-43 \%$.

The polynomial relationship shown in Fig. 8b confirms (see Fig. 3 ) that sulfate anions are not the only acid-forming substrates in the aqueous phase of powder

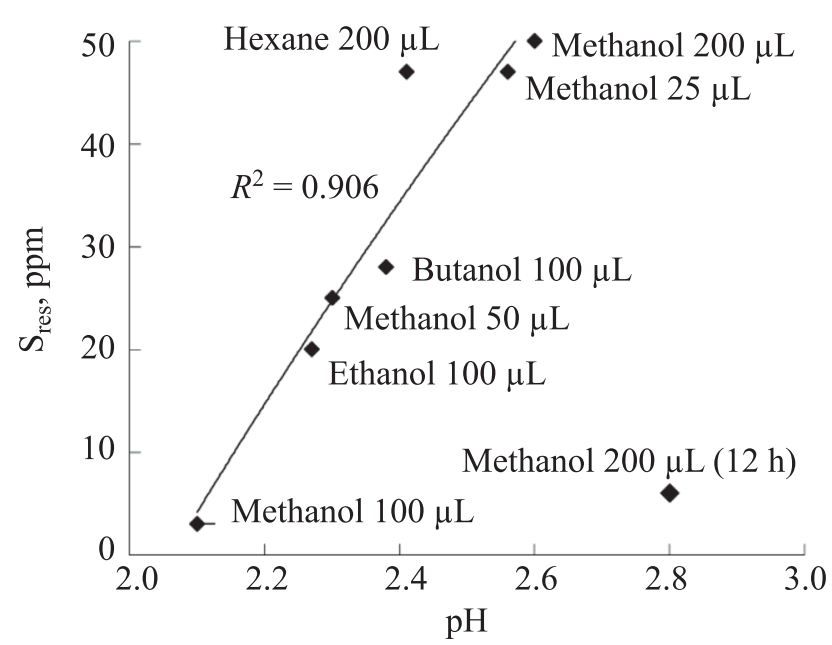

Fig. 7. Residual sulfur in reaction product $\left(\mathrm{S}_{\text {res }}\right)$ as a function of aqueous $\mathrm{pH}$ in powder suspension $\left(\tau_{\mathrm{MA}}=8 \mathrm{~h}\right)$.

suspensions, which are labile (like sulfate anions) and readily hydrolyzed to the corresponding acids.

Recent publications have noted a positive effect of S-O-containing compounds in sulfide catalysts on their activity in HDS processes. However, the true cause of this effect has remained unclear. The above-described findings of the present study are consistent with the conclusions made by other researchers for catalytic systems with a different composition prepared by different methods [16].

The grinding of $\mathrm{MoS}_{2}$ in a dispersed liquid medium results in physical adsorption of the solvent on its surface (a)

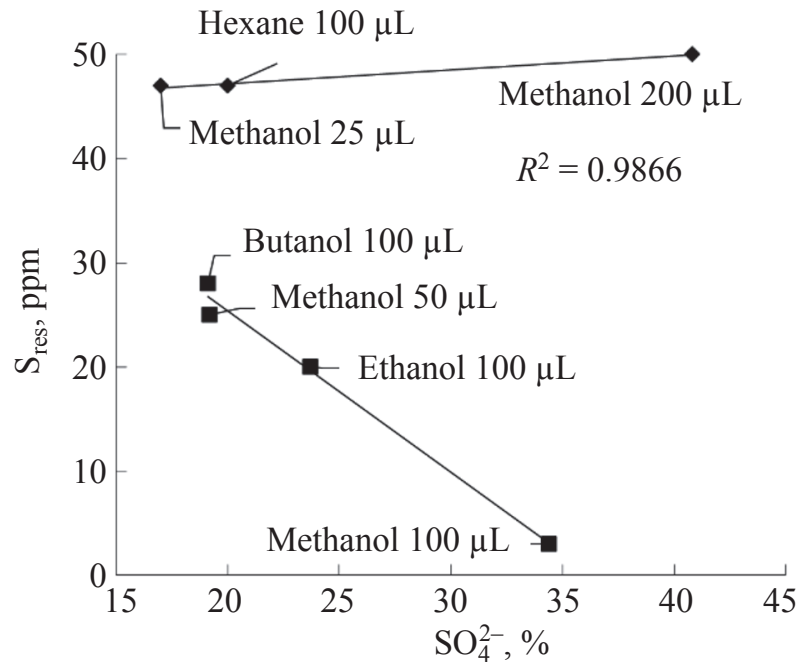

(b)

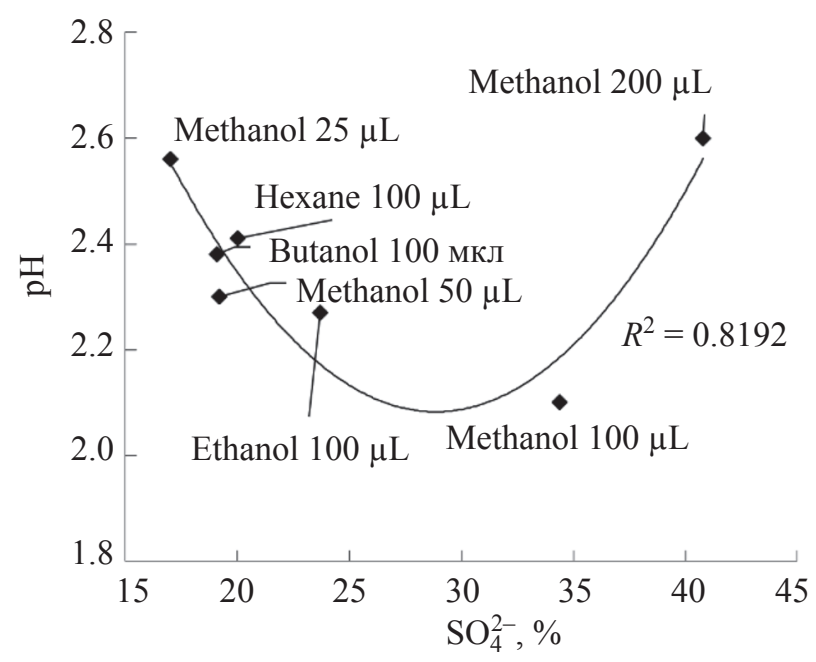

Fig. 8. Effects of surface concentration of sulfate anions: (a) on HDS ability of powders $\left(\mathrm{S}_{\mathrm{res}}\right)\left(\tau_{\mathrm{MA}}=8 \mathrm{~h}\right)$; and (b) on aqueous pH in powder suspension. 
[4]. Therefore, the final physicochemical properties of MA-MoS 2 can be significantly affected by the dielectric permittivity $(\varepsilon)$ of the dispersion medium [17], which, in turn, is a key influencing factor for the Coulomb force between point charges on the surface of the material subjected to grinding. This assumption is supported by the above discussions on the data of Table 2 and Table 3.

The specificity of the $\mathrm{MoS}_{2}$ systems considered in the present study stems not only from the variety of types and amounts of dopant liquids, but also, as a result, from the non-uniformity of the chemical composition of the nanocrystallite surfaces generated. These surfaces consist of different combinations of ions, Mo oxides, $\mathrm{SO}_{4}^{2-}$ groups, as well as $\mathrm{S}-\mathrm{H}$ and $\mathrm{S}-\mathrm{O}$ structural fragments (Fig. 3). Given that the separation degree of induced charges in the prepared powder samples (as listed in Table 3) will be different for each individual $\varepsilon$ value, it is reasonable to anticipate different contributions of dopants to the catalytic activity of MA samples. To the best of our knowledge, such an approach to the evaluation of the effects of dopant's trace amounts has never been considered in published reports.

Figure 9 illustrates an indirect relationship between the dielectric permittivity (within the $\varepsilon$ range of 2 to 33 ) of organic liquids used in this study as dopants and the catalytic activity of the Mo-based powders $\left(\tau_{\mathrm{MA}} 8 \mathrm{~h}\right.$, dopant volume $100 \mu \mathrm{L}$ ).

Figure 9 clearly demonstrates that the DBT-HDS ability of the MA samples in the model reaction $\left(\mathrm{S}_{\text {res }}\right)$ varies from 3 to $47 \mathrm{ppm}$ (as presented in Table 3). This suggests that the MA powder preparation conditions that were implemented ensure free and uniform access for the dopants to the substrate surface. The function in Fig. 9 is symbatic: an increase in the dopant's dielectric permittivity corresponds to an increase in the HDS ability

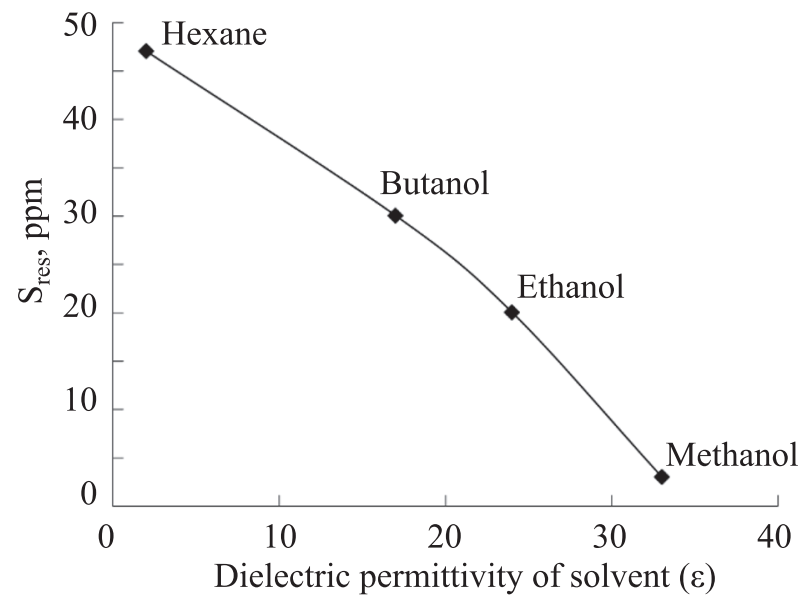

Fig. 9. Catalytic activity of powder as a function of dielectric permittivity of organic liquid ( $\tau_{\mathrm{MA}} 8 \mathrm{~h}$, dopant volume $\left.100 \mu \mathrm{L}\right)$.

of the MA sample. This plot is consistent with the data in Table 2.

Among the dopants examined, sample S-2 ( $\left.* \mathrm{MoS}_{2}+100 \mathrm{CH}_{3} \mathrm{OH}(8)\right)$ has the highest HDS ability (see Table 3). The catalytic activity of this sample proved to remain unchanged ( $\left.\mathrm{S}_{\text {res }} \leq 3 \mathrm{ppm}\right)$ after five (5) service cycles and even after 6-month storage. Importantly, this ability is reproducible without intermediate regeneration of the sample surface, provided that the sample is stored under a solvent bed.

Table 4 presents the data on hydrotreatment of mixed DF with a high presence of sulfur, nitrogen, and aromatic hydrocarbons. The initial composition in the presence of $* \mathrm{MoS}_{2}+100 \mathrm{CH}_{3} \mathrm{OH}(8)$ is provided.

The presence of heteroaromatic nitrogen compounds and polyaromatic condensed structures in the feedstock is well known to significantly complicate the hydrotreatment process [18]. This is due to competition and blockage of catalytically active sites, as well as their poisoning.

Table 4. Characteristics of mixed DF produced in the presence of $* \mathrm{MoS}_{2}+100 \mathrm{CH}_{3} \mathrm{OH}(8)$ hydrotreatment catalyst

\begin{tabular}{c|c|c|c|c|c|c|c|c}
\hline \multirow{2}{*}{ Feedstocke } & \multirow{2}{*}{$\begin{array}{c}\mathrm{S}, \\
\mathrm{wt} \%\end{array}$} & \multirow{2}{*}{$\begin{array}{c}N, \\
\mathrm{ppm}\end{array}$} & $\rho, \mathrm{g} / \mathrm{cm}^{3}$ & \multirow{2}{*}{$\begin{array}{c}\text { Cetane index } \\
\text { (calculated) }\end{array}$} & \multicolumn{4}{|c}{ Aromatic compounds, wt \% } \\
\hline $\mathrm{DF}^{\mathrm{a}}$ & 2.082 & 184 & 0.8574 & 49 & 22.92 & 11.15 & 1.84 & polycyclic \\
\hline \multicolumn{1}{c}{$\begin{array}{c}\text { Initial sulfur content in DF: } 2.082 \mathrm{wt} \% \\
\text { Total aromatics in DF: } 48.90 \mathrm{wt} \%\end{array}$} \\
$\begin{array}{c}\text { Sulfur in hexadecane-diluted DF: } \mathrm{S}_{\text {init }}=500 \mathrm{ppm} \\
\text { Sulfur after DF hydrotreatment: } \mathrm{S}_{\text {res }}=62 \mathrm{ppm}\end{array}$
\end{tabular}

a Composition of mixed DF: $90 \%$ straight-run DF $+10 \%$ catalytic cracking DF from Ryazan refinery; temperature range: $180-360^{\circ} \mathrm{C}$. 
Obviously, the DF group composition presented in Table 4 is too hard for hydrotreatment under relatively mild temperature and pressure conditions indicated.

Nonetheless, the HDS of DF components over $* \mathrm{MoS}_{2}+100 \mathrm{CH}_{3} \mathrm{OH}(8)$ resulted in a 8 -fold reduction in residual sulfur $\left(\mathrm{S}_{\text {res }}=62 \mathrm{ppm}\right)$. According to published data, the hydrogen excess in hydroprocesses generally amounts to 200-600-1000-1200 times [19]. The experimental conditions implemented in the present study correspond to a four-fold $\mathrm{H}_{2}$ deficiency, which serves as evidence of a considerably higher resource provided by the novel catalysts studied here.

\section{CONCLUSIONS}

Under the conditions of solid-phase mechanical activation of molybdenite in an inert atmosphere containing small amounts of polar/nonpolar liquids, novel unsupported bulk single-component sulfide catalysts with high hydrodesulfurization ability were prepared for the first time. It was demonstrated that trace amounts of polar and nonpolar liquid dopants can significantly affect the dispersion, surface chemical state, and catalytic activity of powders, all in accordance with the dielectric permittivity of the organic dopants. The defect level of MA molybdenite nanocrystallites is not a decisive criterion of their catalytic activity. The chemical degradation of the samples in the air was found to lead to the formation of surface sulfate anions that shield the catalytically active sites, potentially Mo ions in various oxidation states. Being responsible for the agglomeration of nanoparticles, the sulfate anions shield active sites, thus contributing to maintaining the initial activity level of nanodispersed molybdenite samples for extended periods (6-12 months). The reaction mechanism of DBT hydrogenolysis is fairly consistent with the cracking route. Even under hydrogen deficiency in the reactor, the presence of a methanol-containing $\mathrm{MoS}_{2}$ intercalate $(100 \mu \mathrm{L})$ ensures a six-fold reduction in the sulfur content of the diluted DF.

\section{AUTHOR INFORMATION}

T.A. Fedushchak, ORCID: http://orcid.org/0000-00032441-8148

M.A. Uimin, ORCID: http://orcid.org/0000-0003-39068101

V.V. Maikov, ORCID: http://orcid.org/0000-0003-40284354

A.S. Akimov, ORCID: http://orcid.org/0000-0001-79531477
S.P. Zhuravkov, ORCID: http://orcid.org/0000-0003-0127$302 X$

A.V. Vosmerikov, ORCID: http://orcid.org/0000-00027569-0902

I.P. Prosvirin, ORCID: http://orcid.org/0000-0002-03515128

L.M. Velichkina, ORCID: http://orcid.org/0000-00023137-3796

A.A. Stepanov, ORCID: http://orcid.org/0000-0003-16605568

V.M. Kogan, ORCID: http://orcid.org/0000-0002-39991855

\section{FUNDING}

The study was carried out within the framework of the Fundamental Research Program of the State Academies of Sciences and the State Assignment (project 02952021-0004, theme "Magnet," State Register Entry no. AAAA-A18-118020290129-5).

\section{CONFLICT OF INTEREST}

The authors declare no conflict of interest requiring disclosure in this article.

\section{OPEN ACCESS}

This article is licensed under a Creative Commons Attribution 4.0 International License, which permits use, sharing, adaptation, distribution and reproduction in any medium or format, as long as you give appropriate credit to the original author(s) and the source, provide a link to the Creative Commons license, and indicate if changes were made. The images or other third party material in this article are included in the article's Creative Commons license, unless indicated otherwise in a credit line to the material. If material is not included in the article's Creative Commons license and your intended use is not permitted by statutory regulation or exceeds the permitted use, you will need to obtain permission directly from the copyright holder. To view a copy of this license, visit http://creativecommons.org/licenses/by/4.0/.

\section{REFERENCES}

1. Varakin, A.N., Sal'nikov, V.A., Pimerzin, A.A., and Nikul'shin, P.A., Russ. J. Appl. Chem., 2019, vol. 92, no. 12, pp. 1761-1771. https://doi.org/10.1134/S1070427219120186

2. Eijsbouts, S., Mayo, S.W., amd Fujita, K., Appl. Catal. A: General, 2007, vol. 322, pp. 58-66. https://doi.org/10.1016/j.apcata.2007.01.008

3. Polyakov, M., Indris, S., Schwamborn, S., Mazheika, A., 
Poisot, M., Kienle, L., Bensch, W., Muhler, M., and Grünert, W., J. Catal., 2008, vol. 260, no. 2, pp. 236-244.

https://doi.org/10.1016/j.jcat.2008.10.005

4. Kouzu, M., Uchida, K., Kuriki, Y., and Ikazaki, F., Appl. Catal. A: General, 2004, vol. 276, nos. 1-2, pp. 241-249.

https://doi.org/10.1016/j.apcata.2004.08.010

5. Knyazheva, O.A., Baklanova, O.N., Lavrenov, A.V., Buluchevskii, E.A., Drozdov, V.A., Trenikhin, M.V., Leont'eva, N.N., Vasilevich, A.V., and Likholobov, V.A., Kitet. Catal., 2014, vol. 55, no. 1, pp. 121-129. https://doi.org/10.1134/S0023158414010042

6. Fedushchak, T.A., Uimin, M.A., Ermakov, A.E., Akimov, A.S., Shchegoleva, N.N., Petrenko, T.V., Zhuravkov, S.P., and Vosmerikov, A.V., Khim. Interes. Ust. Razv., 2013, vol. 21, no. 6, pp. 683-687.

7. Feduschak, T., Akimov, A., Morozov, M., Uymin, M., Zaikovskii, V., Prosvirin, I., Vosmerikov, A., Zhuravkov, S., Vlasov, V., and Kogan, V., Comptes Rendus Chimie, 2016, no. 19, pp. 1315-1325. https://doi.org/10.1016/j.crci.2016.01.011

8. Startsev, A.N. and Zakharov, I.I., Russ. Chem. Rev., 2003, vol. 72, no. 6, pp. 517-536. https://doi.org/10.1070/RC2003v072n06ABEH000772

9. Gao, D., Si, M., Li, J., Zhang, J., Zhang, Z., Yang, Z., and Xue, D., Nanoscale Res. Lett., 2013, vol. 8, no. 1, article no. 129, pp. 1-8.

https://doi.org/10.1186/1556-276X-8-129

10. Klimov, O.V., Khim. Interes. Ust. Razv., 2011, vol. 19, no. 1, pp. 59-66.
11. Uchida, K., Kuriki, Y., Tasaka, Y., Kamiya, K., Kawai, K., Yoda, S., Oshimura, S., Yumura, M., and Ikazaki, F., J. Soc. Powder Technol., 1997, vol. 34, no. 9, pp. 660-665. https://doi.org/10.4164/sptj.34.660

12. Kimura, K., Trans. MRS. Japan., 2000, vol. 25, pp. $147-$ 150.

13. Sergeev, G.B., Nanokhimiya (Nanochemistry), Moscow: MGU, 2003.

14. Palache, C., Frondel, C., Dana, J.D., Dana, E.S., and Berman, H., The System of Mineralogy, Dana, J.D. and Dana, E.S., Eds., New York: John Wiley \& Sons, 1944, vol. 1, pp. 328-331.

15. Skug, D. and West, D., Bases of Analytical Chemistry, Moscow: Mir, 1979, vol. 1.

16. He, Z. and Que, W., Appl. Mater Today, 2016, vol. 3, pp. 23-56.

https://doi.org/10.1016/j.apmt.2016.02.001

17. Tomina, N.N., Pimerzin, A.A., Loginova, A.N., Sharikhina, M.A., Zhilkina, E.O., and Eremina, Yu.V., Petrol. Chem., 2004, vol. 44, no. 4, pp. 246-249].

18. Fedushchak, T.A., Uimin, M.A., Akimov, A.S., Morozov, M.A., Petrenko, T.V., Vosmerikov, A.V., and Zhuravkov, S.P., Khim. Interes. Ust. Razv., 2016, vol. 24, no. 2, pp. 209-215. https://doi.org/10.15372/KhUR20160213

19. Ovsienko, O.L., Dorokhov, V.S., Guseva, A.I., Krivoruchenko, D.S., Pugacheva, L.V., Sidel'nikov, I.V., and Nikul'shin, P.A., Katal. Prom-ti, 2019, vol. 16, no. 4, pp. 316-328.

https://doi.org/10.18412/1816-0387-2019-4-316-328 